\title{
Composite Wires with High Tensile Core for Wire EDM
}

\author{
J.-P. Kruth(1) $)^{1}$, B. Lauwers $(2)^{1}$, B. Schacht ${ }^{1}$, J. Van Humbeeck ${ }^{2}$ \\ ${ }^{1}$ Division PMA, Dept. of Mechanical Engineering, Katholieke Universiteit Leuven, Belgium \\ ${ }^{2}$ Dept. of Metallurgy and Materials Engineering, Katholieke Universiteit Leuven, Belgium
}

\begin{abstract}
In recent years wire EDM cutting speeds and final surface roughness have been continuously improving. Much higher cutting speeds during roughing and surface roughness values lower than $0.1 \mu \mathrm{m}$ Ra during finishing can be obtained. These enhancements are mostly attributed to the use of more advanced generator technology, but also to the type of wire. This paper discusses the use of new composite wires comprising a high tensile core and several coatings. Several wire compositions are introduced and experimentally tested. The use of a very high tensile core, the application of a layer that prevents the process heat from weakening the wire core and the presence of a superficial top coating with different possible functions are discussed. Results obtained while cutting with prototype wires show that a significant rise in accuracy especially in corner cutting is attained, while the cutting rate is at a comparable level as commercial reference wires.
\end{abstract}

Keywords:

Wire EDM, steel wire, accuracy

\section{INTRODUCTION}

In the first ten years after the introduction of wire EDM in 1969 only standard materials like plain copper or brass (CuZn37) were used as an electrode. At first the machines were equipped with a relaxation generator which necessitated the use of plain copper electrodes with an electrical conductivity of $100 \%$ IACS (International Annealed Copper Standard). Other more resistive electrodes placed a too severe mortgage on the discharging power of the generator. Only after the introduction of static impulse generators, brass wires (only $30 \%$ IACS) became an option. The presence of zinc provided a quick ignition in the smaller working gap. The lower electrical conductivity of the brass wire was overcome by the excellent sparking properties of zinc

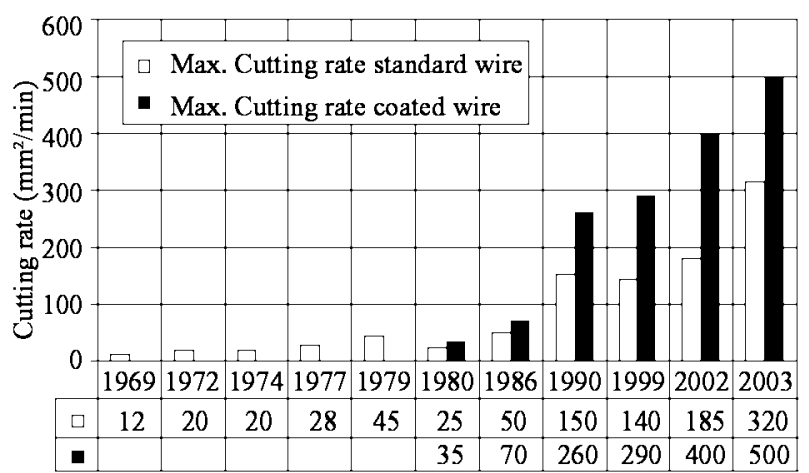

Figure 1: Evolution of wire EDM cutting rate since its invention.

Figure 1 shows a steady increase in maximum attainable removal rate in wire EDM. It was composed from several overview papers [1, 2], recent announcements [3] and experiments performed by the authors. The increased performance of wire EDM with standard wires is to be attributed to more performant generators, higher dielectric inlet pressure, higher wire unwinding speed and an increase in wire diameter. The latter was enabled by the possibility of applying higher currents and shorter pulse on times. Where in 1969 a $150 \mu \mathrm{m}$ wire was used to get to maximum possible cutting rate, in 2003 the thickest available diameter was $360 \mu \mathrm{m}$ [3].

Nowadays plain brass wire is still considered as a standard electrode for machines with a static impulse generator. From 1980 on, Figure 1 shows the tremendous importance of the development of new coated wire electrodes for the exponential increase of cutting rate in wire EDM. These new wires have a copper alloy core and a thick coating with pure zinc or high zinc content, combining high conductivity with good sparking ability.

This paper discusses the development of new wires and complements the features of conductivity and good sparking ability with an increase of accuracy. To attain this a high tensile strength core is chosen, regardless of its electrical conductivity. In this way the applicable load on the wire can be increased to establish more precise machining [4]. Coatings will be added to provide a composite wire with sufficient electrical conductivity and good sparking ability. The following sections will discuss the constituting layers of this composite wire electrode in detail.

\section{HIGH TENSILE STRENGTH: CORE}

Figure 2 gives an Ashby diagram of materials available in wire form and plots their electrical resistivity against their tensile strength. Each bubble represents a number of alloys existing mainly out of the indicated element or crystal structure. It shows that joining high tensile strength (2000 MPa or more) and good electrical conductivity ( $30 \%$ IACS or more, i.e. $7.10^{-8} \Omega \mathrm{m}$ or less) in one material is impossible. To overcome this a composite wire with a high tensile core surrounded by a conductive layer is conceived. By doing so the electrical conductivity and tensile strength of the wire are uncoupled and the core can be chosen to consist out the strongest material.

The composite wires discussed here has a cold worked pearlitic steel core $(0.7 \% \mathrm{C})$. The pearlite is a two-phase 
structure: $\mathrm{Fe}_{3} \mathrm{C}$ and ferrite, formed by an eutectoidic reaction from the austenite phase during cooling. After formation of the pearlite structure by patenting the steel wire at $600^{\circ} \mathrm{C}$, the wire is further cold drawn to the final diameter of a few $100 \mu \mathrm{m}$. During this process the interlamellar distance between the two phases, carbide and ferrite, decreases to below $100 \mathrm{~nm}$ and gets properly oriented while the strength is significantly increased due to both cold deformation and the oriented nanostructure of the pearlite. Such cold processing can create strains of $400 \%$ leading to a tensile strength at room temperature $\left(23^{\circ} \mathrm{C}\right)$ of $4000 \mathrm{MPa}$ or higher.

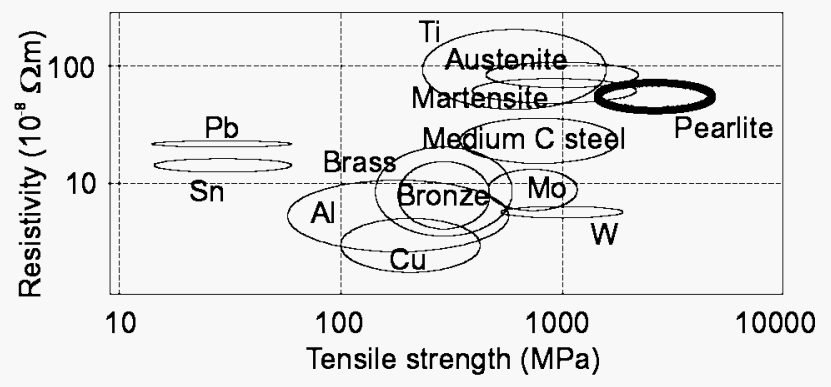

Figure 2: Ashby chart: resistivity vs. tensile strength. At the elevated temperatures of the wire during machining the tensile strength of the pearlitic wire core is slightly lower, while the strain is higher (Figure 3). At $150^{\circ} \mathrm{C}$ which is often referred to as the regime temperature of the wire [4] the tensile strength is still $3500 \mathrm{MPa}$. As Table 1 shows, this is higher than any known wire electrode material in wire EDM. In comparison to Molybdenum wire, that is considered as a competing high strength wire electrode material, the tensile strength is double over the entire temperature range of interest $\left(23-150^{\circ} \mathrm{C}\right)$.

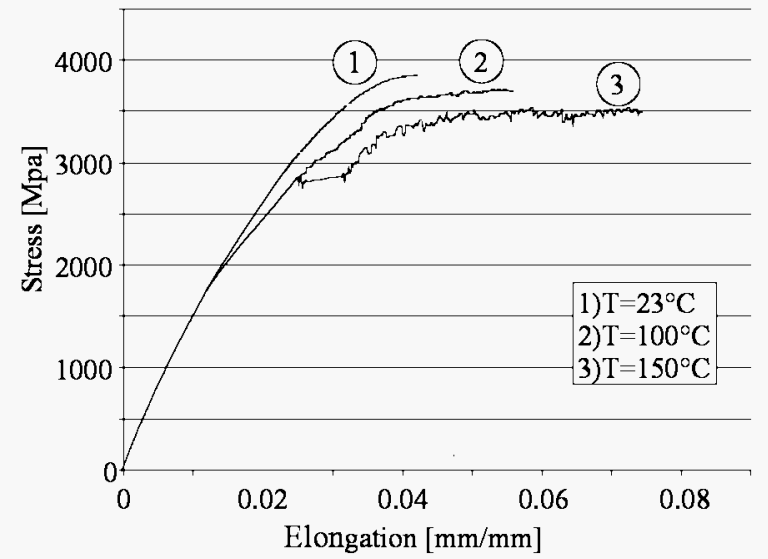

Figure 3: Stress-strain diagram of pearlitic steel core wire at elevated temperature.

\begin{tabular}{llll}
\hline wire material & $23^{\circ} \mathrm{C}$ & $100^{\circ} \mathrm{C}$ & $150^{\circ} \mathrm{C}$ \\
\hline Pearlitic steel & 3850 & 3690 & 3490 \\
Hard Brass CuZn37 & 1035 & 835 & 700 \\
Molybdenum & 1930 & 1820 & 1750
\end{tabular}

Table 1: Tensile strength [MPa] of pearlitic steel wire and common EDM wire electrode materials at elevated temperatures.

Figure 4 illustrates the gain in accuracy if high preloads are applied on a pearlitic steel wire of $100 \mu \mathrm{m}$ diameter: $15 \mathrm{~N}$ can be used, compared to the standard $3.5 \mathrm{~N}$. On molybdenum or tungsten wires of the same diameter the load can only be raised up to $6.5 \mathrm{~N}$. The example given here is for cutting corners of $60^{\circ}$. No corner cutting strategies were used and a sharp edge was produced with the pearlitic steel wire.

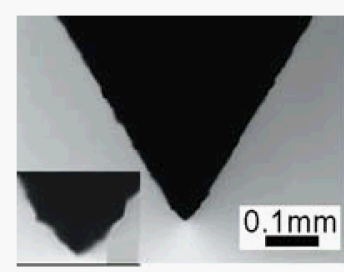

Zn coated copper wire Roughing preload $=3.5 \mathrm{~N}$ 3 finishings preload $=5 \mathrm{~N}$

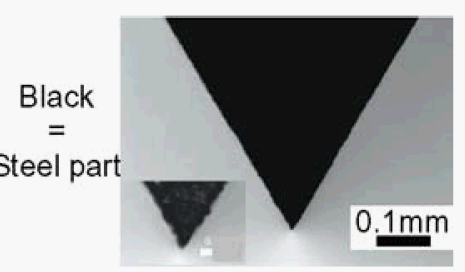

Zn coated steel wire Roughing preload $=14 \mathrm{~N}$ 3 finishings preload $=15 \mathrm{~N}$
Figure 4: Accuracy in corner cutting with low and high tensile strength wires.

\section{ELECTRICAL CONDUCTIVITY: INTERMEDIATE LAYER}

Good conductivity of the wire allows applying high energies to the wire. The generator is essentially a voltage source $[5,6]$. If the same generator settings are used the current delivered to the wire and hence its removal rate will depend on the conductivity of the wire. Table 2 compares the peak current $\hat{T}_{e}$ of steel, brass and copper wires. The lower peak current of steel wires is not only to be attributed to their lower DC resistance, but also to the strongly raising impedance of the wire at higher frequencies due to the skin-effect in the magnetic steel core. In wire EDM the basic frequency of the current signal is as high as $100 \mathrm{kHz}$ for modern machines and still rising with the introduction of newer machines [3]. At this frequency the skin effect forces the current to the outer side of a steel wire. The current is then effectively using a smaller cross-section and the conductivity is lower especially for the thicker wires, e.g. the resistance of a $250 \mu \mathrm{m}$ pearlitic steel wire is 6 times higher at 100 $\mathrm{kHZ}(1.7 \%$ IACS $)$ compared to DC (10\% IACS). For a 100 $\mu \mathrm{m}$ wire it is only 2.5 times higher (4\% IACS). For nonmagnetic materials, such as brass, copper or tungsten and molybdenum, the skin-effect is not significantly present, but might gain importance in the future because of the higher frequency of current impulses on modern machines.

\begin{tabular}{lll}
\hline Material (conductivity [\% IACS]) & $100 \mu \mathrm{m}$ & $250 \mu \mathrm{m}$ \\
\hline Copper (100\% IACS) & $300 \mathrm{~A}$ & $455 \mathrm{~A}$ \\
\hline Brass (26\% IACS) & $275 \mathrm{~A}$ & $432 \mathrm{~A}$ \\
\hline $\begin{array}{l}\text { Pearlitic steel (10\% IACS) } \\
(0.2-1 \mu \mathrm{m} \text { zinc on top) }\end{array}$ & $235 \mathrm{~A}$ & $403 \mathrm{~A}$ \\
\hdashline $\begin{array}{l}\text { Pearlitic steel with copper } \\
\text { intermediate layer (30\% IACS) }\end{array}$ & $271 \mathrm{~A}$ & $430 \mathrm{~A}$ \\
$(0.2-1 \mu \mathrm{m}$ zinc on top) & & \\
\hline
\end{tabular}

Table 2: Peak current $\hat{l}_{\mathrm{e}}$ for wires with changing electrical conductivity (discharge current rise time $=0.4 \mu \mathrm{s}$ ).

The conductivity of a wire electrode can be varied in two ways. First of all the core can be altered. As shown in Figure 2, choosing a highly conductive core has its implication on tensile strength and is therefore not an option in this work. The second method consists of applying a conductive layer in between the core and the outer coating. The latter is to be preferred for the use of the high tensile pearlitic steel core. The conductive layer will be electrically in parallel to the core. Copper is chosen as a low cost conductive material. For wires of $250 \mu \mathrm{m}$ a layer of $10 \mu \mathrm{m}$ copper is adhered to the steel wire, for 100 $\mu \mathrm{m}$ wires the layer is only $4 \mu \mathrm{m}$. By using these values the DC conductivity of both wires is increased to the level of a brass wire (30\% IACS). Applying a thicker layer has several drawbacks. Not only should it be cladded on the wire, but the core filament would take a smaller amount of 
the cross-section and the overall tensile strength of the wire would drop.

At $100 \mathrm{kHz}$ the conductivity of the copper coated steel wires is still $17 \%$ IACS for the $250 \mu \mathrm{m}$ wire and $22 \%$ IACS for a $100 \mu \mathrm{m}$ wire. It is clear that the drop in conductivity is damped by applying the intermediate layer on the wire, since the current that is forced out of the core is given a conductive path. This is also reflected in the attained peak currents given in Table 2. The pearlitic steel wire with copper intermediate layer attains about the same peak current as the brass wire.

\section{SPARKING ABILITY: ZINC BASED COATING}

Now that the basis for a conductive high strength wire is made, a coating must be designed to give the wire good machining performance from the point of view of cutting rate. Many authors $[7,8,9]$ report on the good sparking properties of zinc and its alloys. Tests done by the authors confirm this. Figure 5 shows the maximum cutting rate of $250 \mu \mathrm{m}$ wires with different zinc content in the outer $10 \mu \mathrm{m}$. Only the outer $10 \mu \mathrm{m}$ were considered since it is generally assumed and measured [9] that the EDM crater on the wire side (cathode) is never deeper than 10 $\mu \mathrm{m}$. In Figure 5 the wires with a zinc content smaller than $40 \%$ are plain CuZn alloys, wires with a zinc content higher than $65 \%$ are CuZn37 wires coated with $5,7.5$ or $10 \mu \mathrm{m}$ of pure $\mathrm{Zn}$. The wire with $50 \%$ zinc content is a CuZn37 wire with a thick CuZn50 coating. Due to the brittleness of this beta phase brass no plain wires can be manufactured out of CuZn50.

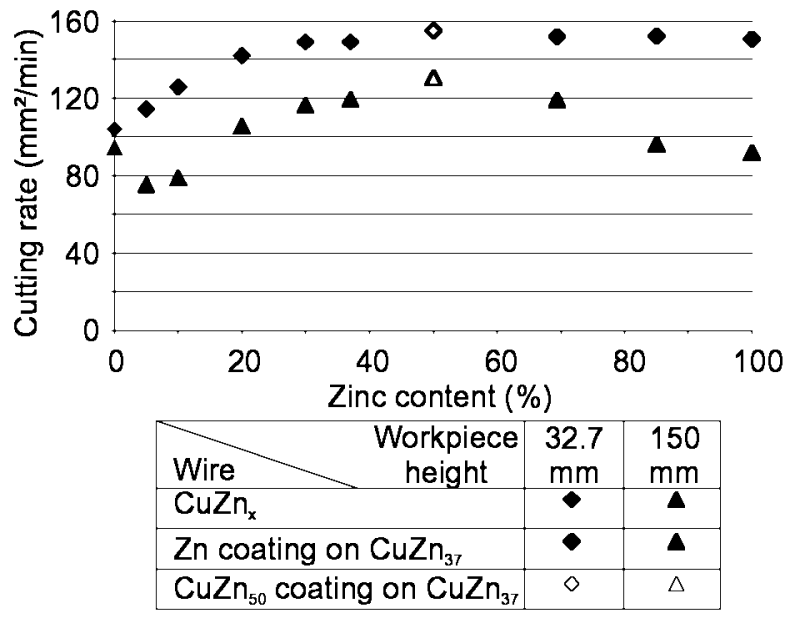

Figure 5: The effect of zinc content in the coating on max. cutting rate $(250 \mu \mathrm{m}$ wires, workpiece: DIN X210CrW12). It is clear that there is a gain in removal rate with zinc content up to $50-60 \%$. For small workpiece heights no further gain is reached for larger contents. For higher workpieces a clear optimum is noticed around this value. The drop in removal rate for larger zinc contents originates from worse flushing conditions leaving an overcontaminated gap and an excess of short circuits and arcs. For high workpieces and small zinc contents (CuZn5, CuZn10) also a significant drop in cutting rate is noticed (w.r.t. Cu, CuZn20) due to the strong reduction of the electrical conductivity of the wire when adding only a small amount of zinc to the copper matrix.

As Figure 6 shows, similar results were obtained with pure zinc coatings on a pearlitic steel wire of $100 \mu \mathrm{m}$ diameter at different axial preloads. A significant increase in the maximum cutting rate is reached for zinc coating thicknesses up to 1-2 $\mu \mathrm{m}$. With larger zinc coatings there is only a slight gain. The Figure also makes clear that the cutting rate increases when a larger preload is applied. This is to be attributed to the diminished vibration of the wire resulting in a more stable machining situation. By measuring the pulses it was shown that increasing the preload from $3.5 \mathrm{~N}$ to $15 \mathrm{~N}$ made short circuits vanish and increase the number of normal pulses from $73 \%$ to $91 \%$. Accordingly, the number of arcs dropped from $25 \%$ to $9 \%$. For zinc coatings thicker than $1 \mu \mathrm{m}$ the cutting rate seems to be rather changeable with altering preloads due to the larger contamination of the gap. It can be expected that $100 \mu \mathrm{m}$ wires with an even thicker coating will result in a lower removal rate due to overcontamination. No tests were done with thicker coatings.

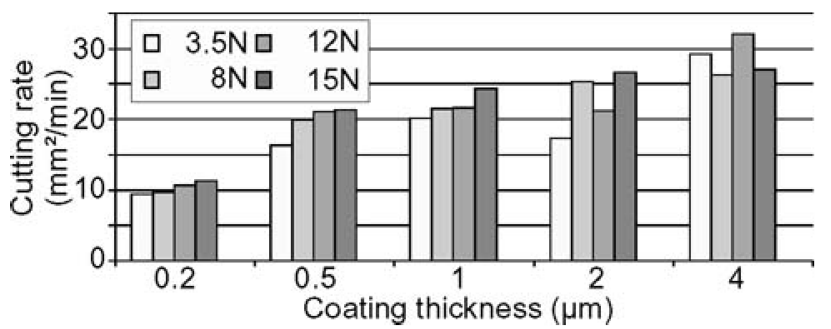

Figure 6: The effect of zinc coating thickness on maximum cutting rate for different pre-loads $(100 \mu \mathrm{m}$ pearlitic steel wire, workpiece: DIN X210CrW12, height $40 \mathrm{~mm}$ ).

\section{ADDITIONAL PERFORMANCE: SUPERFICIAL COATING}

The wire's performance can be enhanced by applying a very thin superficial layer of only some nanometers on top of the wire's coating. This coating can have various purposes: raising cutting speed, enhancing accuracy or contact resistance.

\subsection{Removal rate}

Experiments were performed with varying superficial coatings on a $100 \mu \mathrm{m}$ pearlitic steel wire with $1 \mu \mathrm{m}$ zinc coating. Figure 7 summarises the results. Phosphates and chromates were applied [10]. A clear enhancement of removal rate was noticed. By measuring the appearing pulses, it was revealed that the wires with phosphate and chromate layer had a considerably lower number of short circuits and a higher number of normal pulses in comparison to the wire without superficial coating. The absence of short circuits results from the electrically insulating properties of the layers. The roughing of the zinc coating by etching it in phosphoric acid also led to an improvement of the wire's performance, which should be explained by enhancement of the spark ignition by the higher electric field at roughness peaks.

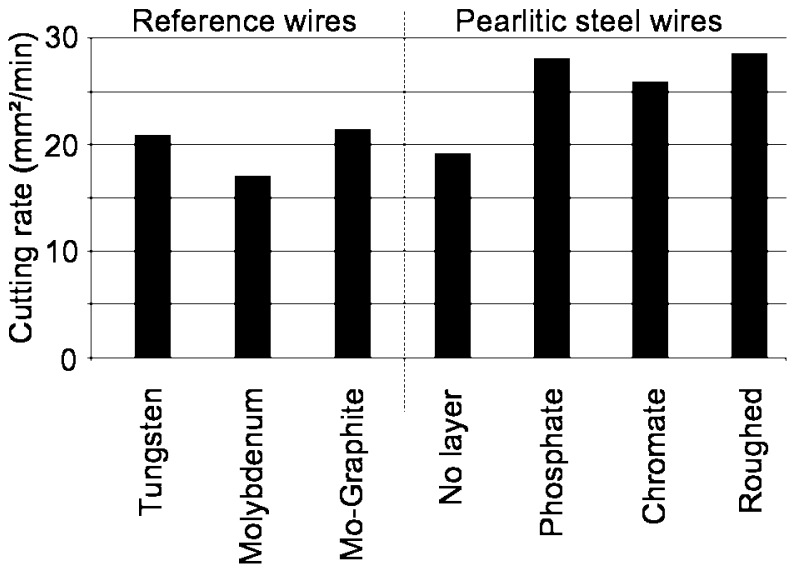

Figure 7: Application of several superficial layers on 100 $\mu \mathrm{m}$ pearlitic steel wire with $1 \mu \mathrm{m}$ zinc coating.

The positive effects of superficial layers on removal rate confirms the finding of Tomalin[11] who discussed the use of graphite particles in the surface of a molybdenum 
wire. The nature of this effect also lies in the enhanced sparking probability due to the present graphite grains. Figure 7 includes the measurement of the removal rate of these wires (Molybdenum and Mo-graphite). Also in [1] Dauw mentions the positive effect of zincoxides on a wire electrode. They have a considerably lower Fermi energy and can hence more easily create electrons for igniting the spark. The cutting speed of wires with an oxide containing coating is better than wires with a pure $\mathrm{Zn}$ coating. The phosphates and chromates used in this research have similar properties

\subsection{Contact resistance}

A good conductive outer layer on the wire gives low contact resistance between the wire and the current contacts. This means that the working current will be slightly higher, because, as said before, the generator is essentially a voltage source $[5,6]$. In this work it was tried to lower the contact resistance by introducing copper particles in the top of the coating. However experiments only showed a slight increase of the machining speed that could not be proven to be significant.

\subsection{Accuracy}

Superficial layers can also be used to enable precise touching of the wire during alignment of the workpiece. Examples are known where silver coatings are applied [12]. This possibility is only mentioned here for reasons of completeness as it was not examined in this study.

\section{THERMAL INSULATION OF THE CORE}

It is important that the mechanical properties of the wire, and hence mainly the core, are safeguarded during machining. Not only can the tensile strength be influenced (Figure 3) but also thermal cracks can appear by the heat of the process. To prevent this thermal deterioration of the core a thermal insulation of the core is considered. FEM simulation of the behaviour of wires with and without an intermediate thermal insulation layer indicated that such layers could effectively prevent the EDM craters to attack the steel core while keeping its temperature low [13]. A prototype wire of this kind has been developed and tested. An electrically conductive but thermally insulating layer, is applied in between the pearlitic steel core and the coating. Figure 8 shows this wire after sparking. In this case it is a $200 \mu \mathrm{m}$ steel wire with a $1 \mu \mathrm{m}$ zinc coating and it is compared to a wire without insulating layer. The very broad and shallow craters indicate that most of the discharge heat has been consumed in the coating and has not been introduced in the core of the wire. As a consequence the mechanical properties of the wire will be kept more constant during machining. A less thick zinc coating will be needed to create the optimal contamination of the sparking gap as the present zinc is more effectively used.

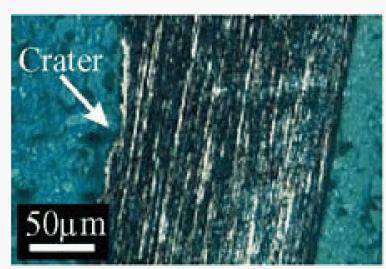

(a)

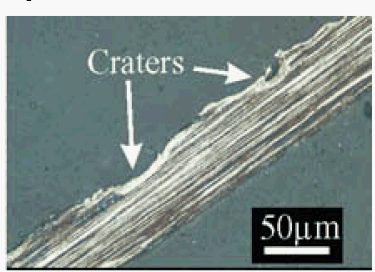

(b)
Figure 8: Shallow crater present on $200 \mu \mathrm{m}$ wire with thermally insulated pearlitic steel core (a) and deep craters on $100 \mu \mathrm{m}$ pearlitic steel wire without insulating layer (b).

\section{CONCLUSION}

This paper gives a basis for the design of composite wires. Attributing one function to every part of the layer makes it possible to produce a wire with a high strength core, good conductivity and good sparking ability. The functional decomposition breaks the wire up into a maximum of 5 parts: a high tensile core, possibly an insulating layer, the conductive intermediate layer, a coating and a superficial layer for sparking ability and extra features such as accuracy and contact resistance. For every part a material can be chosen to perform the needed function. New materials like pearlitic steel, phosphates and chromates are introduced in wire electrodes. Results are given for several composite wires: some with small diameter $(100 \mu \mathrm{m})$ for high precision applications and some with thick diameter $(250 \mu \mathrm{m})$ for applications where high parts are cut. The coated pearlitic wire is shown to be a cheaper and even more performant tool for high precision cutting.

\section{ACKNOWLEDGEMENTS}

The authors acknowledge the support of n.v. Bekaert s.a. as the supplier of the experimental steel wires discussed in this paper and Charmilles Technologies s.a. for providing them with suited EDM machinery.

\section{REFERENCES}

[1] Dauw, D. F., Albert, L., 1992, About the evolution of wire tool performance in wire EDM, Annals of the CIRP Vol. 41/1:221-225.

[2] Kracht, E., Schumacher, B., 1979, Stand der technologie des Schneiderodierens, Industrie Anzeiger 101:34-36.

[3] Waurzyniak, P., 2003, EDM and hard milling boost die/mold productivity, Manufacturing Engineering:99-107.

[4] Dekeyser, W. L., 1988, Knowledge-based system for wire-EDM, Ph.D. thesis K.U.Leuven.

[5] Wollenberg, G., Schulze, H. P., Pape, T., Läuter, M., 1999, Moderne Generatortechnik für die funkenerosiven Bearbeitung, 4. Aachener Fachtagung "Funkenerosiven Bearbeitung".

[6] Schacht, B., Kruth, J. P., Lauwers, B., Vanherck, P., 2004, The skin-effect in ferromagnetic electrodes for wire-EDM, accepted for publication in IJAMT

[7] Sho, H., Orimo, T., Fukui, M., 1989, The effect of electrode materials on the characterisation of machinability of wire electro-discharge machines, Proceedings of ISEM IX:219-222.

[8] Hensgen, G., 1984, Werkzeugspezifische Einflüsse beim funkenerosiven Schneiden mit ablaufender Drahtelektrode, Ph.D. thesis RWTH Aachen.

[9] Perez, R., Chiriotti, N., Demellayer, R., Flükiger, R., Zryd, A., 2001, Investigation of physical processes in wire-EDM by means of single and multiple discharge measurements and analysis, Proceedings of ISEM XIII:473-483

[10] Gonnissen, D., Vanvooren, W., 2001, Electrical discharge machining wire, patent W00189750, Bekaert SA NV

[11] Tomalin, D., 1986, Moly-wire - a breakthrough in cutting speed it ain't necessarily slow, EDM digest. Vol.VIII:3:18-23.

[12] N., 2001, Moswire the solution to your EDM wire demands, Berkenhoff Gmbh.

[13] Schoonjans, S., Vanmarcke, M., 2003, Steel core wire electrodes for EDM: physical approach and optimisation (in Dutch), Master's thesis, K.U.Leuven. 